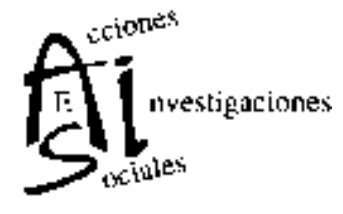

\title{
Sexo, género y transexualidad: de los desafíos teóricos a las debilidades de la legislación española
}

\author{
Katrina Belsué Guillorme \\ mkbelsue@hotmail.com \\ MÁSTER UNIVERSITARIO EN RELACIONES DE GÉNERO \\ UNIVERSIDAD DE ZARAGOZA
}

Resumen: El siguiente trabajo aborda la transexualidad desde la perspectiva del género y el sexo entendidos como elementos socialmente construidos. Pone de relieve de qué forma el interés por perpetuar las normas de género hegemónicas lleva a patologizar a las personas transexuales, lo que las conduce a una construcción consciente del género y el sexo elegidos. También acomete un análisis de la legislación española respecto de esta cuestión, mostrando los avances logrados en los últimos años. Asimismo, expone las debilidades y contradicciones de esta regulación y los problemas que plantea la aplicación a las personas transexuales de la normativa en la que interviene el género. Por último, se realiza una breve referencia al emergente movimiento transfeminista.

Palabras clave: Transexualidad, Género, Transfeminismo, Patologización, Legislación.

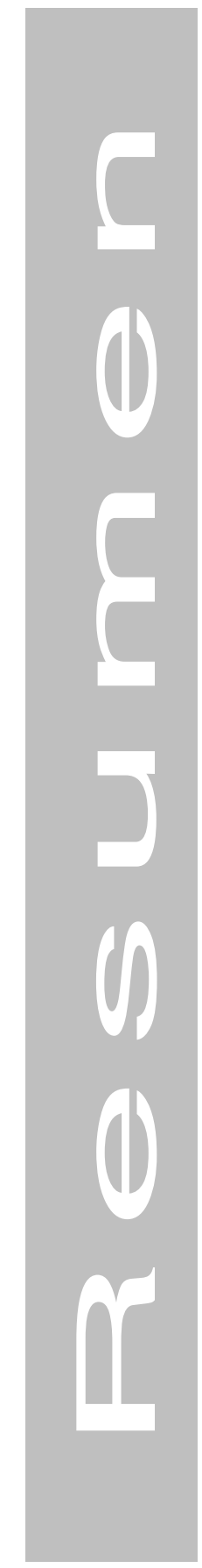




\title{
Sex, gender and transsexuality: from the theoretical challenges to the weaknesses of the Spanish legislation
}

\begin{abstract}
The following abstract discusses transsexuality from the perspective of gender and sex, understood as socially constructed. Points up how the interest in perpetuating the hegemonic gender standards leads to pathologize transsexual people, which leads to a conscious construction of their gender and their sex. It also undertakes an analysis of the Spanish legislation on this issue, showing the progress made in recent years. It also exposes the weaknesses and contradictions of this regulation and the problems posed by the implementation to transsexuals the gender involved regulations. Finally, there is a brief reference to the emerging transfeminist movement.
\end{abstract}

Keywords: Transsexuality, Gender, Transfeminism, Pathologizing, Legislation. 


\section{Sexo, género}

y transexualidad: de los

desafíos teóricos a las

Katrina debilidades de la legislación española

\section{Introducción}

La investigación de la que se da cuenta aquí se ha enfocado desde una perspectiva del género distinta de la socialmente establecida. La militancia en diversas entidades sociales y nuestro trabajo con personas que no cumplen las categorías sociales hegemónicas -entre ellas, personas transexuales- nos llevó a reflexionar sobre las situaciones de opresión que provoca la rigidez de las categorías. Concretamente, en los dos últimos años hemos tenido la oportunidad de mantener una relación cercana con tres personas transexuales que, en un clima de confianza, han tenido la generosidad de contarnos sus experiencias y sentimientos ${ }^{1}$. Sus historias de vida nos han mostrado la opresión que genera el sistema binario sexo/género y la lucha constante, incluso aunque sea involuntaria, que supone vivir fuera de las normas establecidas.

Por otro lado, hay que reseñar que en las últimas décadas y, en particular, desde los años noventa del siglo veinte, una parte del pensamiento feminista ha introducido novedosas y sugerentes formas de conceptualizar el sexo y el género que, a su vez, han incidido de modo crucial en la comprensión de la transexualidad desde una perspectiva no patologizadora. Son ele-

\footnotetext{
${ }_{1}^{1}$ Dos transexuales de hombre a mujer y uno de mujer a hombre.
} 
mentos clave en esta nueva orientación a la que aludimos, de una parte, la desnaturalización no solo del género, sino también del sexo y la sexualidad y, de otra, las propuestas que abogan por la flexibilización y proliferación de las categorías, para permitir que las diversas identidades sexuales y de género encuentren un reconocimiento vital. Una de las pensadoras más representativas en esta visión del género es la filósofa Judith Butler. Por ello, en este trabajo, hemos querido hacer una crítica a la rigidez del sistema sexo/género y mostrar otras posibilidades a través del análisis de la transexualidad y su interpretación desde el pensamiento de esta filósofa.

\section{Breve referencia al sistema sexo/género}

En este trabajo nos aproximamos a la transexualidad como exponente de la construcción cultural del género y a los problemas que plantea el sistema sexo/género en relación con aquella. Esto se manifiesta de manera primaria y patente en la obligación que contraen las personas transexuales de cumplir con las imposiciones sociales atribuidas a cada género, incluso con algunas de aquellas contra las que se dirigen las políticas de igualdad derivadas del feminismo. $Y$ deben someterse a tal exigencia no solo para conseguir ser identificadas en el género deseado -el que no se corresponde con el sexo que tienen asignado- sino porque un cumplimiento exhaustivo de los roles de género correctos es requisito indispensable, de acuerdo con los protocolos médicos vigentes, para lograr finalizar el llamado proceso de transición, si así lo desean². Por ello queremos referirnos brevemente al denominado sistema sexo/género.

Desde que Simone de Beauvoir escribió "No se nace mujer, se llega a serlo" en su libro El segundo sexo, editado por primera vez en 1949, los conceptos de sexo y género y su interrelación han sido objeto de reflexión para las diferentes teorías feministas. El pensamiento de Beauvoir y su interpretación constituyen la base de las teorías sobre el género que, con el objetivo de

${ }^{2}$ En este contexto, se denomina transición el periodo durante el que se prolongan los tratamientos encaminados a obtener el físico atribuido socialmente al sexo deseado. 
superar las posturas esencialistas que reconocían en la configuración genital el destino vital de las personas, elaboraron a partir de los años 60 del siglo veinte las diferentes corrientes feministas. Ya en los años 70 del siglo pasado el feminismo anglosajón elabora el sistema sexo/género como categoría de análisis del pensamiento feminista. Aunque no ha tenido una significación unánime, la más divulgada es aquella que identifica el sexo como una entidad biológica a la que se superpone el género, esto es, el conjunto de factores culturales y sociales que se le asocian. Sin embargo, el pretendido objetivo de superar el esencialismo ha fracasado al mostrar habitualmente la categorización sexo/género aceptando exclusivamente una combinación posible entre los dos sexos y los dos géneros. Una consecuencia clara de ese modo dicotómico y rígido de entender la diferencia sexo/género es la consideración de la transexualidad como patología.

Pero en las dos últimas décadas hemos asistido a la aparición de voces críticas que han cuestionado radicalmente el binarismo de género y el carácter natural del sexo, y que han promovido las identidades de género difusas o la proliferación de estas. Nos estamos refiriendo, en particular, al pensamiento y activismo conocido como movimiento queer y, especialmente, al pensamiento feminista de la filósofa norteamericana Judith Butler. El pensamiento queer propugna la ruptura de los dualismos de género desde la perspectiva de la multiplicación de las categorías identitarias. En este contexto, Judith Butler -una de las pensadoras más interesantes de este nuevo feminismo surgido en los años noventa del siglo pasado- aboga por una sociedad en la que proliferen géneros diversos y por un reconocimiento de los géneros múltiples que ya existen. Para esta filósofa, género, sexo y sexualidad son performativos y son tres de los vectores fundamentales -otro podría ser la raza- a través de los cuales el contexto nos hace. Para ella ninguno de estos tres ejes está inscrito en el cuerpo sino que son construidos culturalmente. Continuamente las personas se hacen y deshacen en su relación con los otros, las hace el contexto, y por ello su identidad es variable y está en continuo proceso de formación. Butler considera inseparables el feminismo y los derechos de las minorías sexuales. Así mismo, afirma que las normas de género llevan siempre implícitas una sexualidad y oprimen a toda persona 
que no cumpla con ellas, de ahí que afecten especialmente a quienes más se alejan de ellas, las minorías sexuales y, por supuesto, las personas trans.

\section{La opresión de las normas de género}

Conviene precisar que el sexo y el género no han sido considerados binarios a lo largo de la historia, ni en todas las sociedades, incluso actualmente existen culturas en las que se admite la pluralidad de ambos. Sin embargo, la definición de la transexualidad y su consideración como enfermedad es muy reciente. El término transexualismo es utilizado por primera vez en 1910 y con su significado medicalizado no se aplicó hasta 1949. El interés radica en saber por qué las variantes de género no normativas han sido perseguidas y actualmente patologizadas en la mayoría de las sociedades occidentales.

Una de las posibles explicaciones del rechazo a la multiplicidad de géneros se encuentra en el uso del poder. Para el ejercicio de este resulta necesario el binarismo constituido por dominadores y dominados, y una de sus representaciones más útiles ha sido el binarismo de género. La defensa de la división hombre/mujer, que permite la jerarquización de ambas categorías, ha propiciado una visión rígida y heterosexista del género. Este enfoque ha provocado el rechazo y la persecución de las minorías sexuales y de transexuales y transgénero. Los movimientos de liberación llegaron también al género y lograron que en los países occidentales la transexualidad dejara de perseguirse penalmente. Sin embargo, la necesidad institucional de evitar la quiebra del sistema sexo/género ha conllevado la consideración de esta como una patología. En los siguientes párrafos queremos dar cuenta de la posibilidad de una visión distinta del sexo y el género que los defina como elementos construidos socialmente. $Y$ es, precisamente, el modo en que la transexualidad hace evidente la construcción aquello que la convierte en peligrosa. En consecuencia, mediante la patologización se pretende el control de la amenaza y la salvaguarda del sistema heteropatriarcal.

Para realizar nuestra crítica al sistema sexo/género a través de la consideración actual de la transexualidad, como ya hemos 
adelantado, estamos interpretando esta basándonos en el pensamiento de Judith Butler. Nos interesa, sobre todo, su defensa del sexo y el género como elementos culturalmente conformados a través de mecanismos performativos, y su planteamiento sobre la importancia del tabú de la homosexualidad en este proceso de identificación. Que el género y el sexo sean construidos no supone que las personas sean libres de modificarlos a su antojo, ya que resulta difícil contrarrestar el poder de las normas de género. Pero los seres humanos tampoco están completamente determinados, porque poseen capacidad de agencia y pueden desarrollarla a través del mismo mecanismo que utiliza el poder para configurarlos. Mediante acciones performativas, de forma consciente o no, se subvierten las categorías impuestas. Esto es precisamente lo que hacen las personas transexuales en el proceso de construcción de su identidad, subvertir las normas para que sus vidas sean consideradas vidas humanas.

En los siguientes párrafos nos referiremos a lo que dicen y piensan las personas transexuales. Estos testimonios provienen fundamentalmente de dos fuentes; de una parte, de los testimonios recogidos en la bibliografía que hemos utilizado $\mathrm{y}$, en particular, del texto Transexualidad y la matriz heterosexual, de Patricia Soley-Beltran (2009); de otra, no podíamos obviar lo que nos han transmitido las personas a las que aludíamos en la introducción (y en la nota 1$)^{3}$. Con ellas no hemos realizado ningún tipo de entrevista; han sido conversaciones personales, en las que han relatado lo que les apetecía, sin que prácticamente realizáramos ninguna pregunta. Somos conscientes de la falta de representatividad estadística que poseen estos testimonios, pero creemos que esa carencia se compensa con otros elementos, que les otorgan un alto valor cualitativo. La intimidad en la que fueron realizados los libera de cualquier sospecha de pre-

${ }^{3}$ Haremos uso de nombres ficticios al relatar sus testimonios y vivencias. Así, Angie es una transexual de hombre a mujer, está casada con un varón y su relación de pareja reproduce roles muy estereotipados. Se realizó la cirugía de reasignación hace ocho meses. Liliana es también transexual de hombre a mujer y está casada con un varón. Fue operada para realizarse el cambio de sexo hace cinco meses. Y Néstor, transexual de mujer a hombre, vive en pareja con una mujer con la que está intentando tener descendencia. A Néstor le realizaron la mastectomía hace un mes y espera fecha para una metadoioplastia. En los tres casos se trata de personas extranjeras, aunque Néstor acaba de obtener la nacionalidad española. 
meditación, algo muy común en las entrevistas a transexuales. Por otra parte, cuando se trata de la posibilidad de hacer habitable una vida, la cuantificación de las personas que viven ese sufrimiento pasa a un segundo plano.

La consideración de la transexualidad como enfermedad ha propiciado que la vida de las personas incluidas en ella sea una vida menos vivible y menos valiosa, ya que han pasado a ser vidas defectuosas. Se ha convertido en patología el hecho de vivir el género de una forma diferente a la socialmente establecida, poniendo de manifiesto que se otorga una importancia a la genitalidad que no se da a otros rasgos físicos. Si comparamos esta situación con la que hace unos años se daba respecto de la raza encontramos paralelismos significativos. La diferencia radica en que mientras que la adjudicación de cualidades innatas a un color de piel, hoy en día, se considera una aberración, en el caso del sexo y el género no solo no se rechaza sino que incluso se fomenta. Se ha creado una enfermedad donde no existía y se ha inventado la transexualidad. Una patología en la que las personas supuestamente enfermas son abocadas a intentar cumplir con todos los requisitos para ser diagnosticadas y cuyo tratamiento es un remedio que refuerza la afección. Esto es así porque la mayor parte de la clase médica ha venido manteniendo que estas personas presentan una incoherencia entre el sexo y el género que es imposible de modificar. Consideran que ambos son elementos inmutables. Desde esta perspectiva se ofrece como única salida la modificación corporal, mediante hormonas y/o cirugía de reasignación, para crear una ficción de sexo. Esto conduce a la paradoja de que la imposibilidad de sanación se produce precisamente porque no hay nada que sanar.

En España se aplican unos criterios médicos generales pero con variaciones en las distintas comunidades autónomas. $Y$ tales criterios conducen a la estereotipación de estas personas. En Aragón, en concreto, se realiza una primera entrevista con el servicio de psiquiatría en la que, de no acertar con las respuestas adecuadas no se recibe el diagnóstico de transexualidad. Los cuestionarios incluyen, entre otras, preguntas sobre el color favorito o los juguetes preferidos en la infancia. Si se supera ese examen, en el cual estas personas han dicho lo que creen que su psiquiatra quiere oír, se produce la derivación al Servicio de Endocrinología que, de no existir contraindicaciones, comienza 
el tratamiento hormonal. Durante los dos años en que es obligatorio seguir este, antes de la cirugía, se debería producir un seguimiento psicológico que no se está llevando a cabo. Por último, para obtener el informe favorable para el cambio legal de sexo o para la realización de la cirugía de reasignación, se lleva a cabo una nueva entrevista en psiquiatría, de alcance y contenido arbitrarios, en la que, en muchas ocasiones, se valoran aspectos tales como la existencia de una relación de pareja heterosexual y, en su caso, se hace hincapié en cuestiones como la maternidad.

Pero el problema no radica en la transexualidad sino en que esta no sea aceptada socialmente, lo que provoca malestar en estas personas. Todos los seres humanos necesitan reconocimiento y las personas transexuales desean obtenerlo siendo incluidas en el sexo que supuestamente se corresponde con el género elegido. Para ello van a realizar una serie de actuaciones que les lleven, de una parte, a su categorización médica, de forma que puedan acceder a los tratamientos necesarios para modificar su cuerpo; y de otra, a conseguir reproducir lo más fielmente posible las características que socialmente se han asignado al género en el que desean vivir. La filósofa Judith Butler da cuenta de cómo la actuación de las personas transexuales para construir su identidad pone de manifiesto la performatividad del género y desnaturaliza el sexo. $Y$ eso es lo que queremos mostrar a continuación.

Las personas transexuales procuran crear un género perfecto. Reproducen todos los elementos que la sociedad heteronormativa les reclama. El primer cambio que suelen realizar, cuya importancia en muchas ocasiones se considera mayor que la de la cirugía, es el cambio del nombre propio usado en su vida cotidiana. El nombre es considerado un componente fundamental en la configuración del sexo y el género. Es igual de importante renunciar al antiguo como ruptura con el sexo no deseado, como elegir uno que muestre sin dudas el género optado para vivir. Liliana nos contó que buscó un nombre que le resultase especialmente femenino y que además fuera el de alguna mujer de su familia. En ello se puede ver una forma de identificación con un cierto modelo de mujer. Al abordar esta cuestión no podemos olvidar que uno de los aspectos más problemáticos en el proceso de transición resulta de la disonancia entre el nombre 
que consta en la documentación y el nombre con el que viven. Angie relata la humillación que siente cada vez que acude a una consulta médica y es nombrada por su apelativo de varón. No se siente identificada con él y opina que se está vulnerando su derecho a la intimidad ${ }^{4}$. En suma, el nombre representa para estas personas uno de los elementos más importantes del género vivido y sentido. El reconocimiento de los otros nos configura y no cabe duda de que el nombre es un elemento fundamental a la hora de ser aceptado como varón o como mujer. La necesidad de aprobación social que todos los seres humanos experimentan contiene una presión añadida en el caso de las personas transexuales. Sin ese beneplácito no podrán ser reconocidas ni legal ni médicamente.

Estas personas también intentan adecuar su personalidad a los rasgos entendidos socialmente propios del sexo elegido -por ejemplo, dulzura en las mujeres y asertividad en los varones- $y$ lo mismo realizan con el lenguaje, modificando desde el tono de voz hasta las expresiones empleadas. Si siempre han manifestado rasgos de personalidad adscritos al sexo contrario al biológico lo ven como prueba de su transexualidad. Angie, en repetidas ocasiones, afirma haber sido siempre muy femenina y dulce. Si son aspectos que no formaban parte de su personalidad relatan que los adquieren de forma "natural" durante el proceso de transexualización. Siguen los estándares estéticos, sobre todo las transexuales. En nuestras conversaciones, Angie y Liliana nos dan consejos de belleza para estar más femenina, pretenden enseñarnos a usar tacones e incluso llegan a reñirnos por no usar maquillaje. $Y$ asumen los roles de género hegemónicos. Por ejemplo, las transexuales valoran la maternidad como algo fundamental para sentirse mujer y así lo expresan.

Pero hay dos elementos en los que ponen un especial empeño: la reproducción en sus discursos de la concepción médica del sexo, el género y su interrelación, y el rechazo de la

\footnotetext{
${ }^{4}$ Una de las ocasiones en las que abordamos esta cuestión nos relató cómo le resultaba especialmente doloroso cuando esto ocurría en la consulta de ginecología. Acude a esta consulta para las revisiones de su operación de reasignación y, a pesar de que aún no ha podido realizar el cambio legal de nombre por ser extranjera, posee un informe médico que recomienda el trato con su nombre femenino.
} 
homosexualidad acompañado de un refuerzo extremo de la heterosexualidad, tanto de ellas como de sus parejas.

Las personas transexuales hacen suyo el discurso médico respecto de la identidad. Asumen la diferenciación que desde la medicina se lleva a cabo entre el sexo -como rasgo biológico e inamovible- y el género -como característica interior de la personalidad, pero también inmutable- y la obligación de que ambos se relacionen de modo coherente. Esta visión se ve plasmada en una expresión que es comúnmente utilizada por estas personas: "Soy una mujer atrapada en un cuerpo de hombre" (o viceversa). Desde estos postulados se les conduce a una única solución posible, la transformación de su cuerpo. El sexo biológico no mutará y su identidad de género no puede ser alterada, así que únicamente puede realizarse una modificación de sus cuerpos que conduzca a una apariencia del sexo deseado. La interiorización de este presupuesto médico les hace creer que la cirugía es la única solución posible y que tras ella se abre una nueva vida que en ocasiones comparan con "volver a nacer". Pero la operación no cambia la percepción que la sociedad tiene de la persona, ya que el resultado de aquella no es algo visible exteriormente. El cambio en la imagen pública se logra en mayor medida con la modificación registral de la mención de sexo y, aun así, resulta más complicado de lo esperado. Además, la cirugía no resulta tan sencilla como les habían hecho creer y la recuperación se prolonga durante más tiempo de lo previsto, lo que conlleva dudas sobre la decisión tomada ${ }^{5}$.

Las normas de género tienen una base muy importante en la heterosexualidad. Nos encontramos en una sociedad heteropatriarcal en la que, a pesar de los avances en la percepción de la homosexualidad, la heterosexualidad sigue considerándose lo normal. En 1980 se publica la tercera edición del Diagnostic and

${ }^{5}$ En los ocho meses que han transcurrido desde su primera intervención, Angie ha padecido numerosas complicaciones. Su vagina no se ha asentado, ha sufrido dos intervenciones más y está pendiente de una cuarta. Liliana ha tenido problemas con la cicatrización del intestino -con un trozo de este se realiza la vaginoplastia- y ha sido hospitalizada en dos ocasiones; no le han podido garantizar que quede libre de secuelas y durante el periodo postoperatorio afirmó que, de haber estado bien informada de la dureza de la operación, tal vez no se hubiera sometido a ella. 
Statistical Manual of Mental Disorders (DSM-III) ${ }^{6}$, en la que desaparece la homosexualidad del catálogo de patologías y se introduce la transexualidad, lo que en nuestra opinión da cuenta de la interrelación que se establece entre ellas, aunque se categoricen de diferente modo. Por este motivo, las personas transexuales sienten la necesidad de alejarse de la homosexualidad ya que temen que se les confiera esa consideración y no se les reconozca la transexualidad. Para ello transforman sus deseos homosexuales, respecto de personas de su sexo biológico, en heterosexuales, al considerarse pertenecientes al otro sexo. En nuestra experiencia hemos encontrado ejemplos de este interés en mostrar su heterosexualidad. Néstor se encuentra a la espera de jurar la Constitución española (último trámite en la obtención de la nacionalidad) y poder así realizar su cambio legal de sexo. Además, desea ser padre y casarse con su pareja. Sin embargo, a pesar de que en España está permitido el matrimonio homosexual y pueden acceder a los tratamientos de fecundación, quieren esperar a obtener la modificación registral del sexo para que "el matrimonio sea heterosexual desde el primer momento"

La heterosexualidad es, por tanto, un componente que pesa sobre las personas transexuales, a la hora expresar y reproducir las normas sociales de género. Las personas transexuales sienten partes sexuadas y no sexuadas en su cuerpo. Circunscriben las sexuadas a los genitales y creen que estos, en ocasiones, no responden de la forma adecuada. A este respecto, Patricia Soley-Beltran (2009: 293-294) reproduce la narración de varias personas transexuales que afirman tener deseos masculinos, aunque sus genitales femeninos producen unos síntomas de excitación erróneos. Se imaginan que deberían tener otros síntomas de excitación acordes con su género (y lo mismo sucede en el otro sentido, de hombre a mujer). Si sienten deseos por una mujer como un hombre, pero sus órganos son de mujer, se trataría, entonces, de homosexualidad, extremo que rechazan. Por ello, en el desarrollo de su sexualidad inten-

${ }^{6}$ EI DSM es un catálogo de enfermedades mentales publicado por la American Psychiatric Association y empleado internacionalmente.

${ }^{7}$ En el mismo sentido se expresaban Angie y su pareja durante la tramitación de su expediente matrimonial aunque en este caso finalmente no fuera posible. 
tan reafirmar su heterosexualidad. Procuran mantener prácticas en las que no intervengan los órganos genitales primigenios cuando todavía los conservan. Si se trata de transexuales de hombre a mujer tratan de mantener una actitud pasiva en las relaciones sexuales -activa en el caso de la transición de mujer a hombre-. Así mismo, defienden que existe una forma diferente de vivir el sexo por mujeres y varones. En el caso de ellas -afirman- debe consistir en algo sentimental y menos necesario, y en el de ellos, en algo físico a lo que siempre deben estar dispuestos. Les resulta primordial la penetración para sentirse mujer u hombre y de esta forma cumplir con la heterosexualidad obligatoria. Al expresar las motivaciones para someterse a la cirugía de reasignación, Angie decía lo siguiente: "por fin podré tener relaciones como las mujeres". Y una vez realizada la operación, la capacidad de cumplir con la penetración vaginal sigue teniendo gran trascendencia. A Liliana le preocupaba si su pareja iba a sentir placer en la penetración y tanto ella como Angie relatan los avances en la funcionalidad de la vagina como pasos especialmente relevantes en su nueva vida. En los casos de las tres personas de las que venimos hablando (Angie, Liliana y Néstor), la preocupación no reside solo en demostrar su heterosexualidad sino también la de sus parejas.

Una cuestión, a nuestro entender significativa, reside en el hecho de que en los países donde la homosexualidad goza de una mayor tolerancia social el número de personas que buscan el reconocimiento como transexuales es menor. Parece que de esta manera se pone de manifiesto la fuerza que la heterosexualidad tiene en las normas de género y cómo la aceptación de la homosexualidad las flexibiliza.

Todo lo expuesto en los párrafos anteriores muestra la manera en que las personas transexuales se construyen a sí mismas, creando un género perfecto que les permita el acceso al sexo deseado. Como ya hemos señalado, en esta construcción no realizan algo distinto de lo que de forma inconsciente hacen el resto de las personas. Muestran así cómo el género no es innato y cómo la significación del sexo también es algo cultural. A través de un proceso de citación reiterada, los componentes de la heterosexualidad normativa intervienen también en la configuración del cuerpo y consiguen confeccionar una correlación sexo/género/orientación sexual que se ajuste a la social- 
mente exigida. En este desarrollo no nos muestran una realidad sino que crean y recrean esa realidad. La sociedad les dice cómo deben sentir las mujeres (o en su caso los varones) y si quieren ser mujeres, pero sienten algo diferente, se fuerzan a cambiar para ser reconocidas como "verdaderas" mujeres.

Por otra parte, las personas transexuales no solo reproducen las normas de género y ponen de manifiesto la forma en que estas dificultan su vida, sino que también evidencian otras discriminaciones que conllevan estas reglas, como la derivada del sexismo. Son objeto de un trato diferente al cambiar de género. En un reciente incidente con la policía, a Néstor lo trataron de forma brusca hasta que comprobaron que, según su documento de identidad, era mujer ${ }^{8}$. En un reportaje del diario Público $^{9}$, una profesora de universidad transexual se pronunciaba en los siguientes términos: "Fue muy curioso. Pasé de ser un macho alfa a ser una hembra zeta. Te das cuenta, como mujer, de que algunas personas te toman por tonta cuando antes, al verte y tratarte como hombre, pensaban que eras listo". En ocasiones, las personas transexuales no desean tanto pasar a un nuevo sexo como no ser consideradas dentro del asignado al nacer. Intentan reproducir las normas del género asignado al nacer, incluso acentuadas, para no ser "discriminadas" y en los momentos en que pueden dejar de hacerlo se sienten aliviadas. Todo lo que venimos desarrollando en este apartado nos lleva a preguntarnos si en otro contexto social desearían haber cambiado de sexo.

Hasta ahora hemos examinado la forma en que las personas transexuales intentan ajustarse al máximo a lo que les dicen que debe ser el género por el que han optado. Sin embargo, existen otras personas transexuales y transgénero que pretenden ser reconocidas como tales. Quieren vivir el género como algo en constante proceso de formación donde no exista la obligación de alcanzar una meta concreta, a no ser que se considere como tal un estado de constante transición, como sucede en algunos de los actuales colectivos transexuales, transgénero y transfe-

${ }^{8}$ Creemos conveniente señalar que el trato volvió a ser vejatorio cuando por la declaración de Néstor la policía descubrió que era transexual.

9 Se trata del reportaje titulado "Integración trans», aparecido en la citada publicación el 17 de mayo de 2010. 
ministas. Este planteamiento queda bastante bien perfilado en las palabras de la activista transexual Norma Mejía (en Nieto Piñeroba, 2008: 67):

Soy una transexual que no se toma por mujer sino que se acepta como transexual. La diferencia es grande. [...] la transexual que se considera simplemente una transexual, de entrada rechaza, generalmente solo interiormente pues de cara al exterior hay que hacer concesiones para sobrevivir, el binarismo que le impone la sociedad, no acepta que tenga que elegir entre ser hombre y ser mujer pues sabe, pues siente, que ella no es ni una cosa ni otra y le parece evidente que las etiquetas no se corresponden con realidades. Por ello, aunque vote a la extrema derecha, es una revolucionaria, porque no acepta los paradigmas de sexo/género en los que se basa nuestra cultura, porque sabe que los géneros, tal como los definen los estereotipos, no existen en realidad, que son una mentira que a la fuerza los dominadores, los agresivos, los violentos, han impuesto a los débiles. Para ella el derecho a la diferencia es el derecho a ser lo que se es, y no es que haya los diferentes y los no diferentes, sino que todos somos diferentes.

Resulta muy complicado contabilizar la población transexual. Por una parte, porque no existe unanimidad sobre quién es o quién puede considerarse transexual, si no nos centramos exclusivamente en las personas diagnosticadas. Por otra, existen hasta el momento muy pocos estudios al respecto, de forma que en España se manejan cifras muy dispares, que dependen de la fuente manejada y que van desde las ocho mil a las cincuenta y cinco mil. Pero el dato que se mantiene constante en estos estudios es la proporción tres a uno, de transexuales de hombre a mujer, respecto de la otra orientación, de mujer a varón (Nieto Piñeroba, 2008: 347-349) ${ }^{10}$. Antes de iniciar nuestra investigación conocíamos el hecho de que el número de transexuales de mujer a varón era muy inferior al de hombre a mujer. Asimismo, sabíamos que no todas estas personas tienen como meta finalizar el proceso de cambio de sexo. Para algunas de ellas el objetivo es permanecer en esa transición. Sin embargo nos ha sorprendido que son significa-

${ }^{10}$ En España, en los últimos años, esta proporción está equilibrándose paulatinamente. 
tivamente más numerosos los transexuales de mujer a hombre que deciden permanecer en posibilidades de género diferentes y no coincidentes con las preestablecidas socialmente. Hemos llegado a la conclusión de que ambos hechos están relacionados y no son casuales. Y aunque es necesario un estudio más detallado, su fundamento podría encontrarse en la distinta forma en que afecta la opresión de las normas de género a varones y mujeres.

\section{La legislación en torno a la transexualidad: avances, debilidades y paradojas}

Nos hemos propuesto también mostrar aquí las contradicciones y paradojas que ponen de manifiesto las leyes que regulan la transexualidad y la aplicación a las personas transexuales de leyes en las que interviene el género. Para que la vida de las personas trans sea más o menos vivible resulta muy relevante la regulación jurídica del derecho a la identidad de género. Por desgracia, esta es prácticamente inexistente y su planteamiento muy reciente. No es hasta el último cuarto del siglo veinte cuando comienza a abordarse la cuestión, tanto en el ámbito internacional como en España. La protección de estas personas ha quedado habitualmente relegada a las cláusulas generales referidas al principio de igualdad, y se ha tratado la identidad de género desde un enfoque patologizador. Sin embargo, en los últimos años han ido surgiendo iniciativas reguladoras que la abordan desde la perspectiva de los derechos humanos. Ejemplo de ello lo constituyen los Principios de Yogyakjarta de las Naciones Unidas, el Informe Hammarberg de la Unión Europea o, ya en España -en Navarra- la Ley Foral 12/2009, de 19 de noviembre, de no discriminación por motivos de identidad de género y de los derechos de las personas transexuales. Esta última fue elaborada con el propósito de constituirse en una ley integral. Reconoce el derecho a la identidad de género, establece medidas para prevenir y combatir la discriminación de estas personas y les proporciona una asistencia integral.

Con ámbito de aplicación estatal, en España se aprueba en 2007 la Ley 3/2007, de 15 de marzo, de la rectificación registral 
de la mención relativa al sexo de las personas. En su proceso de elaboración se perdió la oportunidad de realizar una verdadera ley de género que lo abordase de forma global. La Ley omite la situación de las personas menores de edad y de las extranjeras, a las que deja, por ello, desprotegidas. Respecto de los requisitos exigidos para la modificación legal del sexo y del nombre esta ley supone un avance pero también presenta numerosas deficiencias y contradicciones. El mayor progreso lo constituye la eliminación de la necesidad de someterse a la cirugía de reasignación sexual como requisito inexcusable para la modificación registral. Se trata de una antigua reivindicación de las personas transexuales y los movimientos LGTB y de un primer paso hacia la despatologización de la transexualidad. Numerosas asociaciones y autores como Nieto Piñeroba (2008) consideraban que logrando la supresión de la necesidad de cirugía podían alcanzarse el pleno reconocimiento de derechos de las personas transexuales. Sin embargo, en el poco tiempo pasado desde la aprobación de la Ley 3/2007 ya han quedado de manifiesto sus debilidades. Si bien es cierto que se ha eliminado el requisito de la cirugía, no es menos cierto que se sigue dejando en manos de los médicos la posibilidad del cambio registral. La citada Ley establece la obligatoriedad del diagnóstico de disforia de género que, además, no es suficiente porque debe ir acompañado de un tratamiento durante dos años "para acomodar sus características físicas a las correspondientes al sexo reclamado", tratamiento que habitualmente consiste en una hormonación. Se establece, así mismo, que este requisito podrá ser eximido cuando exista un informe médico que diga que, por razones de salud o edad, está contraindicado. Todo este apartado de la Ley suscita numerosos interrogantes y es fuente manifiesta de inseguridad jurídica. ¿Qué se consideran "características físicas acordes al sexo deseado"? Es decir, ¿qué cantidad de vello, qué tamaño de pechos o qué anchura de cadera se debe tener para ser mujer? Es muy posible que muchas mujeres biológicas no cumplan con los cánones que se les acaban exigiendo a las personas transexuales, y lo mismo ocurriría en el caso de los varones. Pero, además, cuando está contrastado que estos tratamientos tienen innumerables efectos secundarios no se entiende la obligatoriedad de someterse a 
ellos vulnerando el derecho a la integridad física, si la propia ley establece excepciones ${ }^{11}$. Entonces, ies necesario o no un determinado aspecto físico para tener un determinado sexo legal? Si la respuesta es afirmativa no deberían existir excepciones y, llevado el argumento al absurdo, también deberían ser obligatorias determinadas intervenciones para quienes sin ser transexuales no tengan un aspecto suficientemente masculino $o$ femenino, según el caso. Si la respuesta es negativa y lo fundamental es padecer disforia de género, en tal caso, tan solo el diagnóstico debería ser necesario para autorizar el cambio registral y solo una opción personal el someterse a cualquier tipo de tratamiento.

Las contradicciones no terminan aquí. Si, por lo anteriormente expuesto, parece que el punto fundamental de la Ley es el requisito de padecer disforia de género, la propia norma establece una excepción:

DISPOSICIÓN TRANSITORIA ÚNICA: Exoneración de la acreditación de requisitos para la rectificación de la mención registral del sexo. La persona que, mediante informe de médico colegiado o certificado del médico del Registro Civil, acredite haber sido sometida a cirugía de reasignación sexual con anterioridad a la entrada en vigor de esta Ley, quedará exonerada de acreditar los requisitos previstos por el artículo 4.1.

Es decir, las personas que se hubieran operado en el extranjero, sin haber realizado ningún tratamiento médico previo, sin tener ningún informe psicológico, sin hormonación, con el único requisito de haber modificado sus genitales $y$, por tanto, sin un diagnóstico de disforia de género, serán reconocidas con el sexo legal acorde a su genitalidad externa. Sin embargo, una persona que se realice la misma operación fuera de España, tras la entrada en vigor de la Ley, no podrá tener acceso al cambio registral si no cumple el resto de requisitos. Todo lo expuesto nos permite concluir que los requisitos exigidos para permitir el cambio registral de la mención de sexo no son coherentes, se

${ }^{11}$ Todas las personas transexuales con las que he tenido oportunidad de hablar me han comentado las alteraciones que les producía la hormonación (problemas de alergias, de hígado, etc.). Alguna de ellas incluso quería someterse a la operación de reasignación sexual para disminuir la hormonación por los problemas que este tratamiento conlleva. 
modifican según variadas y contradictorias excepciones, sin que permanezca estable e inmutable ninguno de ellos. Lo que a nuestro parecer pone de manifiesto que el interés principal es reforzar la idea de que existen un sexo y un género innatos que van unidos, y que cualquier forma de vida que ponga en cuestión estos principios biologicistas debe ser considerada una deformación. Se van a otorgar ciertos derechos a estas personas, es cierto, pero siempre desde la perspectiva de que la transexualidad se trata de una enfermedad a la que se le da una solución jurídica por no existir curación para ella. Sin embargo, la arbitrariedad que, a nuestro juicio, rezuma la Ley respecto de las condiciones en que cada persona puede acceder a tales derechos pone de manifiesto la imposibilidad de mantener esa correspondencia entre sexo y género que persigue definir de una forma coherente quién es varón o mujer, ya que probablemente ninguna persona cumpla ese ideal imaginado al cien por cien.

En nuestra opinión, lo que debería prevalecer es el derecho a la identidad de género como parte del derecho al desarrollo personal que protege la Constitución española en su artículo 10. En este caso, la intervención médica, como en el resto de características de nuestro desarrollo personal, debería ser voluntaria en todos sus aspectos y, por tanto, el diagnóstico nunca debería ser exigible. Creemos que la elección de género no debería ser considerada en términos patológicos, de la misma forma que ya no se duda de que una determinada orientación sexual deba ser abordada de ese modo. Se podría objetar que el cambio de los datos registrales por mera voluntad crearía una considerable inseguridad en la identificación personal. Pero, si en la actualidad es posible la modificación del nombre propio demostrando que en la vida diaria se utiliza uno diferente al inscrito en el momento del nacimiento, ¿por qué no sería posible hacer lo mismo con el sexo? En todo caso, nuestra propuesta de intervención no se detiene ahí. Piénsese, por ejemplo, en otro elemento vinculado a la apariencia externa de las personas, como es la etnia, que no aparece en la documentación oficial (incluso está prohibido realizar registros basados en ese dato). Si la igualdad plena y efectiva entre hombres y mujeres es uno de los principios que sostienen el ordenamiento jurídico y la política actual en España; si uno de los principales motivos de la identi- 
ficación legal del sexo era evitar matrimonios homosexuales y estos ya están permitidos, resulta plenamente pertinente cuestionarse la necesidad de conservar la mención del sexo en los documentos oficiales. Si no existe un acto civil que conlleve unos efectos diferentes en función de si lo realiza un hombre o una mujer, ¿no sería posible eliminar también la referencia al sexo en los documentos oficiales? En nuestra opinión no solo sería posible sino beneficioso para lograr la igualdad efectiva a la que nos hemos referido. Todavía podría esgrimirse otra objeción, que no parece insalvable, a saber, que el registro legal del sexo es necesario para aplicar las medidas de acción positiva. Pero este tipo de medidas ya existen para otros grupos sociales -personas con minusvalías o pertenecientes a determinadas etnias- y esta condición no consta en sus documentos, sino que es reconocida en el momento de aplicarse aquellas. De igual manera podría resolverse el expediente en el caso del sexo.

La transexualidad, en su regulación específica, estigmatiza a estas personas y evidencia la necesidad de replantearse los conceptos de sexo y género. Pero esta necesidad de reflexión aún se muestra más palpable, si cabe, cuando se aplican normas en las que el género es un elemento clave. Toda la legislación promulgada en los últimos años para evitar las discriminaciones por razón de género (incluido el caso extremo de la violencia de género) se fundamentan en el carácter binario de este y en la protección de la mujer. Esta interpretación rígida y restrictiva del género es la que conduce a los despropósitos que resultan de su aplicación a las personas transexuales. La modificación registral conlleva que en un solo día se pueda pasar de la consideración de un mismo acto como delito o no. Ya que, por ejemplo, si en una pareja de mujeres biológicas una de ellas es transexual su acto tendrá diferente enjuiciamiento si lo realiza antes o después de haber sido reconocido como varón legalmente. Así, el derecho a medidas de protección por parte de su pareja también dependerá del momento de la inscripción registral. Esto mismo va a ocurrir con medidas de fomento del empleo, la aplicación de criterios de acción positiva, cursos de formación dirigidos a mujeres, etcétera. Resulta sorprendente que no se considere que pueda sufrir discriminación por razón de género una transexual de hombre a mujer si aún no ha sido reconocida legalmente como mujer. 


\section{La transexualidad y los nuevos movimientos transfeministas}

La relación entre feminismo y transexualidad ha resultado problemática durante mucho tiempo. Sin embargo, desde la última década del siglo veinte, de manera progresiva, los movimientos feministas han visto la necesidad de integrar feminismo y transexualidad en una perspectiva común. Pensadoras feministas tan relevantes como Judith Butler defienden la proliferación de identidades y géneros como forma de combatir el sistema sexo/genero que sostiene la sociedad heteropatriarcal. Estas corrientes de pensamiento han dado lugar, desde principios del siglo veintiuno, a un movimiento que cuenta con adhesiones crecientes. Nos referimos al denominado transfeminismo, planteamiento que sitúa la raíz del problema en la dicotomía hombre/mujer, que apuesta por la comprensión de un sujeto fragmentado y por la posibilidad de identidades múltiples y no estables. De esta manera, se hace posible la interrelación del sexo y el género con otros factores como la raza o la clase social, y se favorecen las políticas de coalición con otros grupos sociales. El transfeminismo se manifiesta en el campo del activismo con unas reivindicaciones concretas como son la defensa del propio cuerpo; la supresión de la mención de sexo en los documentos oficiales y la derogación de la prohibición de nombres no acordes con el sexo legal; la no intervención quirúrgica en las criaturas intersex recién nacidas y la lucha contra la patologización de la transexualidad. Este último punto conforma el eje central de la movilización más importante a nivel internacional de este movimiento. Se trata de la campaña STOP Trans Patologización 2012, cuyo principal objetivo se encuentra en la desaparición del Trastorno de Identidad de Género de los principales manuales internacionales utilizados para el diagnostico de enfermedades: el DSM (o Manual de diagnóstico de enfermedades mentales) de la Asociación Americana de Psiquiatría, y la Clasificación Internacional de Enfermedades (CIE), de la Organización Mundial de la Salud.

En este sentido, y como consecuencia de reivindicaciones en el mismo sentido realizadas desde diferentes ámbitos, se han aprobado en España, durante el año 2010, dos iniciativas a favor de la supresión de la transexualidad como enfermedad en los manuales internacionales. Una fue presentada dentro de las 
actuaciones del Gobierno español durante su presidencia de la Unión Europea. Y la otra la promovió el Grupo Parlamentario Socialista en el Congreso. Sería de esperar que, ya que se trata de propuestas del Gobierno y del grupo parlamentario mayoritario, en España se modifique la ley en un sentido coherente con las aludidas iniciativas.

\section{Conclusiones}

La consideración de la transexualidad como enfermedad, a partir de 1949, ha propiciado que la vida de las personas incluidas en ella haya pasado a considerarse una vida defectuosa. Se ha transformado en enfermedad el hecho de vivir el género de una forma diferente a la socialmente establecida, otorgando así una importancia a la genitalidad que no se da a otros rasgos físicos, y se ha inventado la transexualidad. La mayor parte de la clase médica ha venido defendiendo que esta incoherencia entre el sexo y el género de la persona es difícilmente subsanable, ya que considera ambos elementos inmodificables. La única solución propuesta ha sido la modificación corporal, mediante el suministro de hormonas y la cirugía de reasignación, para crear una ficción de sexo. Es decir, se aplica un remedio que refuerza la afección. Esto conduce a la paradoja de que la imposibilidad de sanación se produce precisamente porque no hay nada que sanar.

El verdadero problema reside en el hecho de que la transexualidad no sea aceptada socialmente. Todas las personas precisan reconocimiento $y$, debido a la rigidez del sistema sexo/género, las personas transexuales procuran lograr este siendo incluidas en el sexo que se corresponde con el género elegido, que es el opuesto a su sexo biológico según ese mismo sistema. Para ello van a transitar un camino que les lleve, de una parte, a su categorización médica, como modo de acceso a los tratamientos necesarios para modificar su cuerpo; y de otra, a reproducir lo más fielmente posible las características que socialmente se han asignado al género en el que desean vivir. La filósofa Judith Butler da cuenta de cómo la actuación de las personas transexuales para construir su identidad pone de manifiesto la performatividad del género y desnaturaliza el sexo. 
Y eso es lo que hemos querido mostrar en este trabajo. Las personas transexuales procuran crear un género perfecto reproduciendo todos los elementos que la sociedad heteronormativa les reclama: un nombre que revele inequívocamente su sexo y una personalidad adecuada; siguen los estándares estéticos y asumen los roles de género hegemónicos. Pero, sobre todo, hacen especial hincapié en la reproducción en sus discursos de la concepción médica del sexo, el género y su interrelación, y en el rechazo de la homosexualidad acompañado de un refuerzo extremo de la heterosexualidad.

Para lograr el reconocimiento de las personas trans resulta fundamental la regulación jurídica del derecho a la identidad de género. Esta no ha sido abordada, y de forma aún muy escasa, hasta el último cuarto del siglo veinte. Tanto en España como en el ámbito internacional se ha optado preferentemente por incluir la protección de este derecho en cláusulas generales referidas al principio de igualdad de todas las personas y por elaborar regulaciones con un enfoque medicalizado. Sin embargo, en los últimos años han ido surgiendo iniciativas reguladoras que la abordan desde la perspectiva de los derechos humanos.

En España, por ejemplo, se aprueba en 2007 la Ley 3/2007, de 15 de marzo, de la rectificación registral de la mención relativa al sexo de las personas. Esta ley de ámbito estatal contiene algunos avances, ya que permite la modificación registral de la mención de sexo y el cambio de nombre sin necesidad de someterse a la cirugía de reasignación sexual. Pero esta norma también presenta numerosas deficiencias y contradicciones. No es una ley integral y deja desprotegidas a las personas menores de edad y a las extranjeras. Por otra parte, a pesar de suprimir la cirugía obligatoria, los requisitos exigidos en la ley para el cambio legal de sexo evidencian cómo se continúa tratando la transexualidad como una enfermedad, con los efectos estigmatizadores que de ello se derivan. Además, estos requisitos y sus excepciones no se formulan de manera coherente.

La transexualidad, en su regulación específica, evidencia la necesidad de replantearse los conceptos de sexo y género, y lo hace aún más si cabe cuando se le aplican normas en las que el género es un elemento clave. La interpretación rígida y restrictiva del género puede conducir a despropósitos en la aplicación de tales normas a las personas transexuales. Por ejemplo, 
la modificación registral conlleva que en un solo día se pueda pasar de la consideración de un mismo acto como delito o no, o de ser considerado sujeto de protección a dejar de serlo.

A lo largo de su historia la relación entre feminismo y transexualidad no ha resultado fácil, pero desde hace dos décadas algunos movimientos feministas han visto la necesidad de integrar feminismo y transexualidad en una perspectiva común. Pensadoras feministas como Judith Butler defienden la proliferación de identidades y géneros como forma de combatir el sistema sexo/genero que sostiene la sociedad heteropatriarcal. Y son estas teorías que apuestan por acabar con la dicotomía hombre/mujer las que han dado lugar, desde principios del siglo veintiuno, al movimiento denominado transfeminismo, que, en el campo del activismo, hace suyas las reivindicaciones de los movimientos a favor de la despatologización de la transexualidad.

Este trabajo es una síntesis de una investigación más amplia sobre la transexualidad y todas las cuestiones acometidas aquí merecen, por descontado, un estudio más detenido y de más largo alcance. Nos proponemos continuar con las líneas de análisis apuntadas en las páginas anteriores y adentrarnos en otras que, en relación con la transexualidad, se presentan igualmente atractivas. Es el caso, por ejemplo, de la construcción lingüística del género y de la sexualidad que llevan a cabo las personas transexuales 0 , desde una perspectiva jurídica, de los retos que el cambio de sexo le plantea al derecho internacional.

\section{Bibliografía}

ALVENTOSA DEL RÍO, J. (2008). Discriminación por orientación sexual e identidad de género en el derecho español, Madrid, Ministerio de Trabajo y Asuntos Sociales.

BURGOS DÍAZ, E. (2006). "Haciendo y deshaciendo el género", Riff Raff. Revista de Pensamiento y Cultura, 030, 2. época (pp. 149-164).

BURGOS DÍAZ, E. (2007). "Identidades entrecruzadas", Thémata. Revista de filosofía, 39 (pp. 245-253).

BURGOS DÍAZ, E. (2008). Qué cuenta como una vida. La pre- 
gunta por la libertad en Judith Butler, Bohadilla del Monte (Madrid), Antonio Machado Libros.

BUTLER, J. (2001). El género en disputa. El feminismo y la subversión de la identidad, México, Paidós. Edición original titulada Gender Trouble. Feminism and the Subversión of Identity, Nueva York, Routledge, 1990.

BUTLER, J. (2006). Deshacer el género, Barcelona, Paidós Ibérica. Edición original titulada Undoing Gender, Nueva York, Routledge, 2004.

CABRAL, M. (2005). "La paradoja transgénero", Boletín del Proyecto Sexualidades, Salud y Derechos Humanos en América Latina. La "Perspectiva de género" en perspectiva, o el dilema de los activismos hegemónicos, 18. (Publicado en www.ciudadaniasexual.org [consultada el 15.07.2010]).

GARAIZABAL, C. (2010). "Transexualidades, identidades y feminismos", en M. Missé y G. Coll Planas (eds.), El género desordenado, Barcelona-Madrid, Egales (pp. 125-140).

HAMMARBERG, T. (2009). Derechos humanos e identidad de género. Informe temático. Serie de publicaciones "Transrespeto Versus Transfobia", Volumen I.

HILL, R. y otros. (2002). In the shadows of the arch: Safety and acceptance of lesbian, gay, bisexual, transgendered and Queer students at the University of Georgia, Athens, GA, Department of Adult Education.

MISSÉ, M. (2010). "La lucha trans por la despatologización, una lucha transfeminista", Observatorio igualdad de género (CCOO), 6 (pp. 32-37).

MISSÉ, M. y G. COLL-PLANAS, G. (eds.). (2010). El género desordenado, Barcelona-Madrid, Egales.

NIETO PIÑEROBA, J. A (ed.). (2003). Antropología de la sexualidad y diversidad cultural, Madrid, Talasa Ediciones.

NIETO PIÑEROBA, J. A. (2008). Transexualidad, intersexualidad y dualidad de género, Barcelona, Bellaterra.

PLATERO MÉNDEZ, R. (2009). "Transexualidad y agenda política: una historia de (dis)continuidades y patologización", Política y Sociedad, 46 (1-2) (pp. 107-128).

SOLÁ, M. (2009). "La fragmentación del sujeto y la apertura del género, un nuevo escenario para las luchas feministas", Documentos de las Jornadas Estatales Feministas. La lucha trans por la despatologización (Granada 5, 6 y 7 de diciem- 
bre de 2010). (Publicado en www.feministas.org [consultada 20.08.2010]).

SOLEY-BELTRAN, P. (2009). Transexualidad y la matriz heterosexual. Un estudio crítico de Judith Butler, Barcelona, Bellaterra.

SUESS, A. (2010). "Análisis del panorama discursivo alrededor de la despatologización trans: procesos de transformación de los marcos interpretativos en diferentes campos sociales", en M. Missé y G. Coll Planas (eds.), El género desordenado, Barcelona-Madrid, Egales (pp. 29-54).

\section{Normas legales españolas consultadas}

Ley de 8 de junio de 1957 sobre el Registro Civil.

Decreto de 14 de noviembre de 1958 por el que se aprueba el Reglamento de la Ley del Registro Civil.

Constitución Española (1978).

Ley Orgánica 10/1995, de 23 de noviembre del Código Penal.

Ley Orgánica 1/2004, de 28 de diciembre, de Medidas de Protección Integral contra la Violencia de Género.

Proyecto de Ley reguladora de la rectificación registral de la mención relativa al sexo de las personas (2006).

Ley $3 / 2007$, de 15 de marzo, de la rectificación registral de la mención relativa al sexo de las personas.

Ley 3/2007, de 22 de marzo, para la igualdad efectiva de mujeres y hombres. Ley Foral 12/2009, de 19 de noviembre, de no-discriminación por motivos de identidad de género y de los derechos de las personas transexuales. 